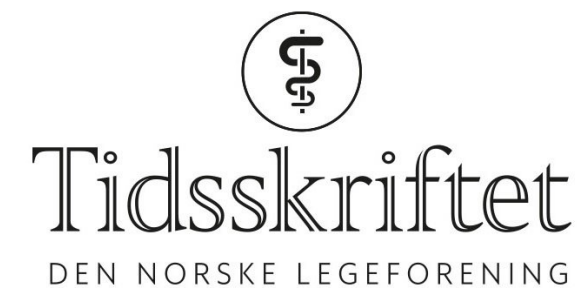

DEN NORSKE LEGEFORENING

\title{
Kronisk tretthet hos voksne kreftoverlevere
}

KLINISK OVERSIKT

\section{KRISTIN VALBORG REINERTSEN}

E-post: kvr@ous-hf.no

Seksjon for brystonkologi

Avdeling for kreftbehandling

Nasjonal kompetansetjeneste for seneffekter etter kreftbehandling

Oslo universitetssykehus

Kristin Valborg Reinertsen (f.1965) er spesialist i onkologi og overlege. I 2011 tok hun doktorgraden på temaet seneffekter etter brystkreftbehandling.

Forfatter har fylt ut ICMJE-skjemaet og oppgir ingen interessekonflikter.

\section{JON HÅVARD LOGE}

Avdeling for kreftbehandling

Regionalt kompetansesenter for lindrende behandling

Oslo universitetssykehus

Jon Håvard Loge (f.1953) er spesialist i psykiatri og i barne- og ungdomspsykiatri. Han er leder for Regional kompetansetjeneste for lindrende behandling, Helse $\emptyset r-\emptyset$ st og professor II ved Avdeling for medisinsk atferdsvitenskap. Han var leder for Nasjonal kompetansetjeneste for seneffekter etter kreftbehandling 2011-14. Fra midten av 1990-årene har han arbeidet med seneffekter etter kreft og spesielt kronisk tretthet hos kreftoverlevere.

Forfatter har fylt ut ICMJE-skjemaet og oppgir ingen interessekonflikter.

\section{METTE BREKKE}

Avdeling for allmennmedisin

Institutt for helse og samfunn

Universitetet i Oslo

Mette Brekke (f.1953) er spesialist i allmennmedisin og professor. I tillegg er hun fastlege ved Kurbadet legesenter, Oslo.

Forfatter har fylt ut ICMJE-skjemaet og oppgir ingen interessekonflikter.

\section{CECILIE E. KISERUD}

Avdeling for kreftbehandling

Nasjonal kompetansetjeneste for seneffekter etter kreftbehandling

Oslo universitetssykehus

Cecilie E. Kiserud (f.1966) er ph.d. og overlege med spesialitet i onkologi. Hun jobber som leder ved Nasjonal kompetansetjeneste for seneffekter etter kreftbehandling.

Forfatter har fylt ut ICMJE-skjemaet og oppgir ingen interessekonflikter.

Uttalt tretthet og slitenhet er vanlig både under og etter avsluttet kreftbehandling. Mellom 15-35\% av voksne kreftoverlevere har kronisk tretthet. Kronisk tretthet hos kreftoverlevere påvirker sosial yteevne, funksjonsnivå og arbeidsevne på en negativ måte, og kan medføre betydelig redusert livskvalitet. 
Uttalt tretthet, utmattelse og slitenhet (fatigue) er et av de vanligste symptomene ved onkologisk behandling (1-3). Hos de fleste vil denne trettheten gradvis forsvinne etter avsluttet behandling, men ikke alle opplever bedring. Opptil $35 \%$ av alle som har gjennomgått kurativ kreftbehandling, og som er uten kjent kreftsykdom, vil oppleve vedvarende tretthet etter avsluttet behandling $(3,4)$. Andre kreftoverlevere kan oppleve en kort periode etter avsluttet behandling uten symptomet for deretter å oppleve redusert energi.

Kronisk tretthet er definert ved at plager som energiløshet og/eller svekket hukommelse og konsentrasjonsevne varer i seks måneder eller mer (5). For de fleste affiserte vil kronisk tretthet negativt påvirke daglig funksjon og arbeidsevne, og kan medføre betydelig redusert livskvalitet (3).

Kreftrelatert tretthet er ingen diagnose i ICD 10, og det finnes ikke etablerte kriterier som bidrar til å klassifisere kreftrelatert tretthet som en egen sykdomstilstand. Kreftrelatert tretthet kan defineres som en subjektiv opplevelse av tretthet, svakhet eller energiløshet (6) eller som en utmattende, vedvarende subjektiv opplevelse av fysisk, emosjonell og/eller kognitiv tretthet, som ikke er proporsjonal med aktivitetsniva $(7,8)$. Selv om utmattelse er et kardinalsymptom også ved myalgisk encefalopati (ME), er ME definert ved forekomst av tilleggssymptomer, for eksempel muskel- og leddsmerter, gastrointestinale plager og/eller ømme lymfeknuter (9). «Chemobrain» (chemotherapy-related cognitive dysfunction) brukes som oftest for å beskrive kjemoterapi-indusert kognitiv dysfunksjon. Symptomene på dette kan overlappe med mental tretthet, men om det er to ulike tilstander eller uttrykk for det samme, vet man ikke.

Denne artikkelen omhandler kronisk tretthet hos kreftoverlevere behandlet for kreft i voksen alder (>18 år). Målet med artikkelen er å informere helsepersonell som møter voksne kreftoverlevere, om forekomsten av kronisk tretthet, assosierte faktorer, utredning og mulige tiltak.

\section{Metode}

Artikkelen er basert på internasjonale retningslinjer for evaluering av kronisk tretthet hos voksne kreftoverlevere $(7,8,10)$, et subjektivt utvalg av aktuell litteratur, egen klinisk erfaring og egen forskning.

\section{Måling og forekomst}

Ulike spørreskjemaer har vært benyttet for å kartlegge forekomsten av tretthet etter kreftbehandling (11). Dette vanskeliggjør sammenligning av resultater fra forskjellige studier. Med skjemaet Fatigue Questionnaire (FQ) måler man graden av fysisk og mental tretthet i tillegg til plagenes varighet (5). Dette spørreskjemaet er derfor anbefalt for flerdimensjonal kartlegging av kronisk tretthet blant kreftoverlevere (11).

Skjemaet ble også benyttet da forekomsten av kronisk tretthet i den generelle norske befolkningen ble undersøkt i 1990-årene. Forekomsten av kronisk tretthet var da 13 \% blant kvinner og $10 \%$ blant menn og lett $\emptyset$ kende med $ø$ kende alder (12). Det er ikke avklart hvor sensitivt spørreskjemaet Fatigue Questionnaire er for endring over tid. I studier hvor man $\emptyset$ nsker å måle dette, kan man derfor vurdere andre instrumenter. I klinisk praksis kan en enklere numerisk skala fra o (ikke tretthet) til 10 (verst tenkelig tretthet) bidra til å kartlegge alvorlighetsgrad av symptomet og synliggjøre endring (7).

Kronisk tretthet er en av de hyppigste seneffektene hos voksne kreftoverlevere. Norske studier har vist at 25-35\% av langtidsoverlevere etter brystkreft, lymfom og livmorhalskreft er plaget med kronisk tretthet (4, 13-15), og $26 \%$ og $13 \%$ av ikke-hormonbehandlede menn rapporterte kronisk tretthet to år etter henholdsvis radikal strålebehandling og radikal prostatektomi for prostatakreft (16). Blant norske overlevere etter testikkelkreft ble det nylig vist at forekomsten av kronisk tretthet økte fra $15 \% 12$ år etter behandling til $27 \%$ syv år senere (17). 
Tretthet er et hyppig problem også blant andre grupper av kreftoverlevere, for eksempel rapporteres forekomster over $40 \%$ blant overlevere etter kolorektal kreft og lungekreft (18-20). Forekomsten av kronisk tretthet i disse gruppene er imidlertid ukjent da varigheten av plagene ikke ble målt. Selv om kronisk tretthet er undersøkt hos andre grupper kreftoverlevere, gjør få studier med varierende metodikk at forekomsten av kronisk tretthet hos disse foreløpig må anses som usikker.

\section{Assosierte faktorer}

Data har tidligere ikke entydig vist sikker sammenheng mellom utviklingen av kronisk tretthet og type eller intensitet av krefthandling (21-23). Nylig ble det imidlertid i en metaanalyse vist at risikoen for alvorlige tretthetsplager hos brystkreftoverlevere $ø$ kte etter kombinasjonsbehandling med kirurgi, kjemo- og stråleterapi, sammenlignet med kirurgi eller kirurgi og stråleterapi alene (24). Strålebehandling har også vært diskutert som en mulig etiologisk faktor for utviklingen av kronisk tretthet ved prostatakreft (16).

Det er bred enighet om at kronisk tretthet blant kreftoverlevere ikke er forklart av sykdomsog behandlingsrelaterte faktorer alene, men at kronisk tretthet er et multifaktorielt fenomen som påvirkes av somatiske, demografiske og psykososiale faktorer (3). Også i den generelle norske befolkningen var sosiodemografiske og helserelaterte faktorer assosiert med kronisk tretthet (12). Å bo alene, ha lav inntekt eller oppleve psykisk ubehag som uro, bekymring, pessimisme og nedsatt stemningsleie/depresjon er assosiert med kronisk tretthet hos kreftoverlevere $(3,15)$.

Bidragende faktorer kan også være komorbide tilstander, eller andre seneffekter og symptomer, slik som kardiovaskulær sykdom, lungesykdom, overvekt, søvnforstyrrelser, hormonforandringer, perifere nevropatier og vedvarende smerteplager $(3,13,14,16,17)$.

Vedlikeholdende faktorer har fått mer oppmerksomhet i de senere årene, spesielt fysisk inaktivitet og katastrofetanker (3). Flere biologiske mekanismer har vært studert som mulige bakenforliggende årsaksfaktorer. Disse har inkludert endringer i hypothalamushypofyse-binyre-aksen, blant annet med dysregulering av glukokortikoidproduksjon og/eller av glukokortikoidreseptor, og endret ATP- og muskelmetabolisme. Av de biologiske mekanismene har det de siste årene vært størst søkelys på inflammasjon som årsak til kroniske tretthetsplager med dysregulering av cytokiner og spesielt proinflammatoriske cytokiner, uten at funnene kan anses som konklusive (3). Inflammasjonshypotesen støttes av relativt konsistente funn om sammenheng mellom blant annet feber, vekttap og nattesvette (B-symptomer) og kronisk tretthet hos lymfomoverlevere. En mulig forklaring på strålebehandling som en etiologisk faktor for utvikling av kronisk tretthet hos overlevere etter prostatakreft kan være at slik behandling, i større grad enn kirurgi, kan indusere langvarige inflammasjonsprosesser (16).

\section{Utredning og vurdering}

Det er svak evidens for hva som er optimal utredning av enkeltindivider med kronisk tretthet etter kreftbehandling (7).Vurderingen må derfor baseres på klinisk skjønn og eventuell tilstedeværelse av risikofaktorer og faktorer som kan bidra til å opprettholde og/eller forsterke symptomene hos hver enkelt. Mulig tilbakefall av kreftsykdommen bør alltid vurderes, spesielt hvis en pasient som følte seg bra, utvikler tretthet.

Basert på internasjonale retningslinjer og Helsedirektoratets anbefalinger i publikasjonen Seneffekter etter kreft beskrives i egen ramme forhold som kan være nyttig å vurdere i møtet med kreftoverlevere som plages av dette symptomet (ramme 1).

Ramme 1 Forslag til utredning av kronisk tretthet hos voksne kreftoverlevere. Oversikten er basert på internasjonale retningslinjer og Helsedirektoratets anbefalinger $(7,8,25)$

Måling av nivået av tretthet (Fatigue Questionnaire eller tilsvarende spørreskjemaer) 
Generell tretthetsanamnese: debut, mønster, varighet, endring over tid, faktorer som forverrer/bedrer plagene, aktivitetsmønster gjennom dagen og uken Andre faktorer

- psykologiske faktorer, spesielt høyt bekymringsnivå og katastrofetanker

- søvn, smerter, medikamenter, misbruk av alkohol eller narkotiske stoffer

- somatisk komorbiditet

- kreftbehandling kan disponere for komorbiditet, for eksempel kardiomyopati etter hjertetoksisk kjemoterapi eller lavt stoffskifte etter strålebehandling mot hals

Generell klinisk undersøkelse bør gjennomføres for å kunne oppdage somatisk sykdom som bakenforliggende årsak. Tilbakefall av kreftsykdommen bør vurderes hvis en pasient som var i god form, utvikler tretthet Supplerende undersøkelser vurderes individuelt

- Aktuelle blodprøver er hematologisk status, hormonprøver (inkludert thyreoideastatus), elektrolytter, lever/gallestatus

- Bildediagnostikk gjøres på klinisk mistanke om somatisk sykdom

- Henvisning til andre medisinske spesialister baseres på funn og klinisk vurdering. Det kan være aktuelt med henvisning til

○ kardiolog etter gjennomgått kardiotoksisk behandling

- nevropsykolog ved hukommelses- og/eller konsentrasjonsproblemer, spesielt hos yngre

○ psykolog/psykiater ved mistanke om psykisk lidelse

- smerteteam

$\circ$ endokrinologisk vurdering

\section{Tiltak}

Tilnærming og rådgivning til en som sliter med kronisk tretthet etter kreftbehandling, må baseres på skjønn og tilpasses individuelt. Dersom det ved utredningen påvises behandlingstrengende somatiske eller psykiske tilstander, må disse behandles. Det finnes ellers ingen spesifikk behandling for kronisk tretthet, men flere tiltak som kan avhjelpe plagene (26).

Generelt anbefaler man at pasienten får oppdatert informasjon om hva kronisk tretthet er og om bidragende og avhjelpende faktorer. Rådgiving om aktivitetsmønster er ofte nyttig fordi mange overforbruker krefter på gode dager for så å bli utslått i flere påfølgende dager, noe som kan føre til nedsatt eller i verste fall avtagende fysisk aktivitet over tid. Råd om energiøkonomisering, med tilpasning av aktivitet i forhold til opplevd energinivå, vil også kunne hjelpe mange til å unngå svingninger og om mulig bidra til gradvis oppbygging av fysisk kapasitet. For alle affiserte er det gunstig å ha en regelmessig døgnrytme og ikke sove på dagtid $(7,8)$.

Øvrige tiltak faller i tre hovedkategorier: fysisk aktivitet, kognitiv terapi og stressreduserende terapier. En nylig publisert metaanalyse viste at trening og psykologiske intervensjoner bedrer kronisk tretthet i omtrent like stor grad. Effekten var like god både ved anaerob og aerob trening, mens av de psykologiske intervensjonene var kognitiv terapi mest effektivt. Alle tiltakene hadde best effekt gitt i grupper (26).

Selv om kronisk tretthet kan være en dynamisk tilstand, foreligger ikke data som konkret angir hvor mange som kan forventes å bli bra etter trening/kognitiv terapi. Enkeltstudier 
har vist lovende resultater av yoga, akupunktur og mindfulnessbaserte tilnærminger (7, 27). Foreløpig kan imidlertid ikke dette anbefales på generelt grunnlag da studiene er få med et begrenset antall inkluderte pasienter og lite data vedrørende effektvarighet.

Uten sikker dokumentasjon kan trekk ved sykehistorien og symptombildet likevel peke mot hva som er den beste tilnærmingen for det enkelte individet. For en som er inaktiv, kan trening kombinert med rådgiving være et godt førstevalg. Ved katastrofetanker og dysfunksjonelle tankemønstre kan kognitiv terapi være et godt førstevalg, mens stressreduserende tiltak kan være et godt førstevalg hos dem med høyt bekymrings- og spenningsnivå.

Et tiltak som er dokumentert effektivt, er regelmessig fysisk trening (28). Hvilken intensitet og type fysisk aktivitet som har best effekt, er ikke avklart. Imidlertid er vår erfaring at det er viktig med et individualisert opplegg, med en rolig start og deretter progresjon, noe som også støttes av litteraturen så langt. Mange vil starte med for høy intensitet med påfølgende treningsavbrudd eller i verste fall forverring av plagene som resultat. For de fleste kreftoverlevere med kronisk tretthet vil et treningsprogram med moderat intensitet, inkludert rask gange, sykling og/eller svømming, være trygt (7). Har pasienten andre seneffekter (kardiovaskulær affeksjon, polynevropati) eller komorbide tilstander må treningsopplegget tilpasses dette.

I ovennevnte metaanalyse beskriver man at trening kanskje er mest effektivt under pågående kreftbehandling, mens psykologiske intervensjoner, eventuelt en kombinasjon av trening og psykologiske tiltak, kan synes best hos kreftoverlevere (26).

Det finnes en rekke rehabiliteringstilbud til pasienter med kronisk tretthet. I tillegg arrangeres mestringskurs for pasienter på enkelte lærings- og mestringssentre og Vardesentre (sentre for kreftrammede og pårørende etablert av Kreftforeningen og helseforetakene på enkelte sykehus). Psykostimulantia (metylfenidat og modafinil) har vært brukt enkelte steder i utlandet, men tilbys ikke disse pasientene i Norge på grunn av manglende dokumentert effekt.

Alt helsepersonell som møter kreftoverlevere, bør ha kunnskap om kronisk tretthet og om tiltak som kan avhjelpe plagene. Selv om enkelte kreftoverlevere kontrolleres hos kirurg eller onkolog, vil likevel fastlegene være dem som oftest møter kreftoverlevere med kronisk tretthet. Fastlegen kan bidra med informasjon om tilstand og tiltak, slik som energiøkonomisering, fysisk aktivitet og kognitiv terapi. Fastlegen vil også ha kunnskap om komorbiditet og risikofaktorer hos den enkelte pasient. Videre vil fastlegen være sentral i administrering av trygdeordninger slik at pasienten kan få en arbeidssituasjon som hun/han kan mestre. Det er derfor naturlig at utredning og oppfølging av disse pasientene først og fremst er fastlegens ansvar.

\section{LITTERATUR:}

1. Stone P, Richardson A, Ream E et al. Cancer-related fatigue: inevitable, unimportant and untreatable? Results of a multi-centre patient survey. Cancer Fatigue Forum. Ann Oncol 20oo; 11: 971 5. [PubMed][CrossRef]

2. Lawrence DP, Kupelnick B, Miller K et al. Evidence report on the occurrence, assessment, and treatment of fatigue in cancer patients. J Natl Cancer Inst Monogr 2004; 32: 40 - 50.

[PubMed][CrossRef]

3. Bower JE. Cancer-related fatigue-mechanisms, risk factors, and treatments. Nat Rev Clin Oncol 2014; 11: 597 - 6o9. [PubMed][CrossRef]

4. Reinertsen KV, Engebraaten O, Loge JH et al. Fatigue during and after breast cancer therapy - a prospective study. J Pain Symptom Manage 2017; 53: 551 - 6o. [PubMed][CrossRef]

5. Chalder T, Berelowitz G, Pawlikowska T et al. Development of a fatigue scale. J Psychosom Res 1993; 37: 147 - 53. [PubMed][CrossRef] 
6. Radbruch L, Strasser F, Elsner F et al. Fatigue in palliative care patients - an EAPC approach. Palliat Med 2008; 22:13-32. [PubMed][CrossRef]

7. Bower JE, Bak K, Berger A et al. Screening, assessment, and management of fatigue in adult survivors of cancer: an American Society of Clinical oncology clinical practice guideline adaptation. J Clin Oncol 2014; 32: 1840 - 50. [PubMed][CrossRef]

8. Howell D, Keshavarz H, Broadfield L et al. A pan Canadian practice guideline for screening, assessment, and management of cancer-related fatigue in adults. Version 2 - 2015, Toronto. http://www.capo.ca (23.8.2017).

9. Egeland T, Angelsen A, Haug R et al. Hva er egentlig myalgisk encefalopati? Tidsskr Nor Legeforen 2015; 135: 1756 - 9. [PubMed][CrossRef]

10. Howell D, Keller-Olaman S, Oliver TK et al. A pan-Canadian practice guideline and algorithm: screening, assessment, and supportive care of adults with cancer-related fatigue. Curr Oncol 2013; 20 : e233-46. [PubMed][CrossRef]

11. Stone PC, Minton O. Cancer-related fatigue. Eur J Cancer 2008; 44: 1097 - 104. [PubMed][CrossRef]

12. Loge JH, Ekeberg O, Kaasa S. Fatigue in the general Norwegian population: normative data and associations. J Psychosom Res 1998; 45: 53 - 65. [PubMed][CrossRef]

13. Reinertsen KV, Cvancarova M, Loge JH et al. Predictors and course of chronic fatigue in long-term breast cancer survivors. J Cancer Surviv 2010; 4: 405 - 14. [PubMed][CrossRef]

14. Seland M, Holte $\mathrm{H}$, Bjøro T et al. Chronic fatigue is prevalent and associated with hormonal dysfunction in long-term non-Hodgkin lymphoma survivors treated with radiotherapy to the head and neck region. Leuk Lymphoma 2015; 56:3306 - 14. [PubMed][CrossRef]

15. Vistad I, Fosså SD, Kristensen GB et al. Chronic fatigue and its correlates in long-term survivors of cervical cancer treated with radiotherapy. BJOG 2007; 114: 1150 - 8. [PubMed][CrossRef]

16. Kyrdalen AE, Dahl AA, Hernes E et al. Fatigue in hormone-naïve prostate cancer patients treated with radical prostatectomy or definitive radiotherapy. Prostate Cancer Prostatic Dis 2010; 13: 144 - 50. [PubMed][CrossRef]

17. Sprauten M, Haugnes HS, Brydøy M et al. Chronic fatigue in 812 testicular cancer survivors during long-term follow-up: increasing prevalence and risk factors. Ann Oncol 2015; 26: 2133 - 40.

[PubMed][CrossRef]

18. Thong MS, Mols F, Wang XS et al. Quantifying fatigue in (long-term) colorectal cancer survivors: a study from the population-based patient reported outcomes following initial treatment and long term evaluation of survivorship registry. Eur J Cancer 2013; 49:1957 - 66. [PubMed][CrossRef]

19. Frick MA, Vachani CC, Hampshire MK et al. Survivorship after lower gastrointestinal cancer: Patient-reported outcomes and planning for care. Cancer 2017; 123: 186o - 8. [PubMed][CrossRef]

20. Huang J, Logue AE, Ostroff JS et al. Comprehensive long-term care of patients with lung cancer: development of a novel thoracic survivorship program. Ann Thorac Surg 2014; 98: 955 - 61. [PubMed][CrossRef]

21. Bower JE, Ganz PA, Desmond KA et al. Fatigue in breast cancer survivors: occurrence, correlates, and impact on quality of life. J Clin Oncol 2000; 18: 743 - 53. [PubMed][CrossRef]

22. Broeckel JA, Jacobsen PB, Horton J et al. Characteristics and correlates of fatigue after adjuvant chemotherapy for breast cancer. J Clin Oncol 1998; 16: 1689 - 96. [PubMed][CrossRef]

23. Kreissl S, Mueller H, Goergen $\mathrm{H}$ et al. Cancer-related fatigue in patients with and survivors of Hodgkin's lymphoma: a longitudinal study of the German Hodgkin Study Group. Lancet Oncol 2016; 17: 1453 - 62. [PubMed][CrossRef]

24. Abrahams HJ, Gielissen MF, Schmits IC et al. Risk factors, prevalence, and course of severe fatigue after breast cancer treatment: a meta-analysis involving 12327 breast cancer survivors. Ann Oncol 2016; 27: 965 - 74. [PubMed][CrossRef]

25. Helsedirektoratet. Seneffekter etter kreft 2017.

https://helsedirektoratet.no/publikasjoner/seneffekter-etter-kreft (23.8.2017).

26. Mustian KM, Alfano CM, Heckler C et al. Comparison of pharmaceutical, psychological, and 
exercise treatments for cancer-related fatigue: a meta-analysis. JAMA Oncol 2017;3: 961 - 8.

[PubMed][CrossRef]

27. Lengacher CA, Reich RR, Paterson CL et al. Examination of broad symptom improvement resulting from mindfulness-based stress reduction in breast cancer survivors: a randomized controlled trial. J Clin Oncol 2016;34: 2827-34. [PubMed][CrossRef]

28. Cramp F, Byron-Daniel J. Exercise for the management of cancer-related fatigue in adults. Cochrane Database Syst Rev 2012; 11: CDoo6145. [PubMed]

Publisert: 27. oktober 2017. Tidsskr Nor Legeforen. DOI: 10.4045/tidsskr.17.0040

Mottatt 11.1.2017, første revisjon innsendt 25.4.2017, godkjent 9.10.2017.

(C) Tidsskrift for Den norske legeforening 2020. Lastet ned fra tidsskriftet.no 